\title{
Família e ciclo vital: a fase de aquisição
}

Family and life cycle: the acquisition phase

Familia y ciclo vital: la fase de adquisición

Juliana Peterle Ronchi*

Luziane Zacché Avellar **

\begin{abstract}
Resumo
Esta pesquisa objetivou descrever as características da fase de aquisição, primeira fase do ciclo vital familiar, marcada pela união do casal e a convivência com os filhos pequenos. $\mathrm{O}$ estudo foi realizado com 50 famílias de classe média, na fase de aquisição do ciclo vital da família, da cidade de Vitória-ES. Os participantes responderam ao questionário baseado na pesquisa Ciclo vital da família paulista, que se mostrou adequado para compreender a dinâmica e os valores das famílias da cidade de Vitória. Os dados coletados foram submetidos ao programa SPSS para Windows e, em seguida, realizamos análise qualitativa dos dados. Em Vitória, a família em fase de aquisição se mostrou mais tradicional, com conflitos relacionados a assuntos de extradinâmica familiar, como dinheiro e satisfação profissional.
\end{abstract}

Palavras-chave: família; ciclo vital; fase de aquisição.

\begin{abstract}
This research aimed at describing the characteristics of the acquisition phase, the first phase of the family life cycle, marked by the union of the couple and the living with small children. The study was carried through with 50 middle-class families, in the acquisition phase of the Family Life Cycle, from the city of Vitória, ES. The participants answered a questionnaire based on the Paulista Family Life Cycle research, which is adequate for the understanding of the dynamics and values of families from the City of Vitória. The collected data was submitted to the program SPSS for Windows and, after that, we performed a qualitative analysis of the data. The family in the acquisition phase from the city of
\end{abstract}

\footnotetext{
Mestranda do Programa de Pós-graduação em Psicologia da Universidade Federal do Espírito Santo (PPGP/UFES), psicóloga.

** Professora doutora do Departamento de Psicologia Social e do Desenvolvimento e do Programa de Pós-graduação em Psicologia da Universidade Federal do Espírito Santo (DPSD/PPGP/UFES).
} 
Vitória was shown to be more traditional, with conflicts related to issues outside the family dynamics, such as money and professional satisfaction.

Keywords: family; life cycle; acquisition phase.

\section{Resumen}

Esta encuesta tuvo como objetivo describir las características de la fase de adquisición, primera fase del ciclo vital familiar, marcada por la pareja y la convivencia con los hijos pequeños. El estudio fue realizado con 50 familias de la clase media, en fase de adquisición del ciclo vital de la familia, en la ciudad de Vitória-ES. Los participantes respondieron al formulario con base en la encuesta Ciclo Vital de la Familia Paulista, que es adecuada para comprender La dinámica y los valores de las familias de la ciudad de Vitória. Los datos recolectados fueron sometidos al programa SPSS para a continuación realizar el análisis cualitativo de los datos. La familia en fase de adquisición de la ciudad de Vitória-ES se mostró más tradicional, con conflictos relacionados a cuestiones de extradinámica familiar, como lo relativo al dinero y la satisfacción profesional.

Palabras clave: familia; ciclo vital; fase de adquisición.

\section{Introdução}

A

família é uma instituição social, que sofre modificações ao longo do tempo, sendo que historicamente se observam várias formas de relações familiares (Prado, 1981; Narvaz \& Koller, 2006). Podemos afirmar ainda, baseando-nos em Prado (1981), Narvaz e Koller (2006) que uma família se constitui por relações expressas diferentemente de acordo com o tempo, o lugar e os papéis que cada um desempenha. Dessa forma, uma das perspectivas utilizadas na investigação dos aspectos familiares pode ser a teoria do "Ciclo Vital Familiar", representada nos Estados Unidos por pesquisadores como Carter e McGoldrick e, no Brasil, por Cerveny e Berthoud (Carter \& McGoldrick, 1995; Cerveny \& Berthoud, 1997; 2002). De acordo com Cerveny e Berthoud (1997; 2002) o ciclo vital da família brasileira subdividese em quatro fases: fase de aquisição, fase adolescente, fase madura e fase última.

Tendo em vista a escassez de pesquisas sobre o ciclo vital da família, nosso estudo objetivou descrever as características da primeira fase do ciclo vital da 
família brasileira, a fase de aquisição, com base na perspectiva de Cerveny e Berthoud (1997; 2002). Segundo Cerveny e Berthoud (1997), em todas as fases do ciclo vital, as pessoas que fazem parte da família estão em processo de aquisição, no entanto a primeira fase do ciclo vital familiar recebe esse nome porque a aquisição é a característica mais central e específica. Assim, os objetivos dessa fase estão em encontrar o lugar para morar, o emprego que proporcione condições de sobrevivência, os acessórios domésticos que facilitam a vida, o carro, o seguro saúde, muitas vezes até a complementação educacional. Os filhos pequenos também fazem parte dessa primeira fase, em que se inicia a aquisição de um modelo familiar próprio, com as pessoas selecionando, entre os modelos adquiridos em suas famílias de origem, aqueles que vão adotar em seu casamento.

Dessa forma, essa fase trata da formação de um novo sistema, que tem como marco o casamento. $\mathrm{O}$ casamento não se limita ao conceito popular de união de duas pessoas, que adquirem a condição de serem pais e que acreditam na possibilidade de êxito da união e, assim, na felicidade dos parceiros. Uma vez encarada a família como um sistema complexo, que se move através do tempo, levando consigo toda uma história, a ideia de união implica a fusão de dois sistemas familiares inteiros, ou seja, os valores, costumes e tradições dos grupos de origem dos parceiros serão redefinidos para a construção de um novo.

A chegada do primeiro filho também é um grande marco na fase de aquisição, indicando a mudança de papéis no sistema familiar. Na pesquisa de Lopes e colaboradores (2006), realizada na Região Sul do Brasil com o objetivo de verificar a relação entre presença de ritual de casamento e planejamento da primeira gravidez, o ritual do casamento esteve mais associado ao planejamento do primeiro filho, enquanto a ausência do ritual de casamento esteve mais associada à ausência de planejamento do primeiro filho. De acordo com os pesquisadores, um ritual de transição, como marca da transição do jovem adulto solteiro para o jovem adulto casado, pode indicar um maior fortalecimento do laço emocional do novo casal, salientando a importância dos rituais familiares como simbolizadores de mudanças.

As formas de se constituir família mostram-se cada vez mais ampliadas, e essas novas formas de relações familiares exercem mudança sobre a sociedade. Prado (1981), por exemplo, afirma que a família pode exercer forte influência sobre seus membros. Dessa forma, por ser um tema complexo e desafiador, e pela escassez de estudos na área, objetivamos gerar conhecimentos sobre estrutura, dinâmica e valores da família de 
classe média de Vitória, Estado do Espírito Santo, na fase de aquisição, possibilitando material de estudo para pesquisadores.

\section{Metodologia}

\section{Participantes}

Cinquenta famílias consideradas de classe média por indicadores como renda familiar, escolaridade, bens e serviços de que dispóem, na fase de aquisição do ciclo vital da família, da cidade de Vitória. ${ }^{1}$

\section{Instrumento}

Os participantes responderam ao questionário da pesquisa Ciclo Vital da Familia Paulista (Cerveny \& Berthoud, 1997), que se mostrou adequado para compreender a dinâmica e os valores das famílias da cidade de Vitória.

\section{Procedimento de coleta de dados}

O estudo contou com uma amostra de conveniência formada por 50 famílias vitorienses da classe média, em fase de aquisição.

Este artigo é fruto dos dados obtidos do projeto de pesquisa apresentado ao Programa Institucional de Bolsas de Iniciação Científica (PIBIC 2007/2008) da Universidade Federal do Espírito Santo, o qual teve o apoio financeiro do Fundo de Apoio à Ciência e Tecnologia do Município de Vitória (Facitec), e seguiu os procedimentos éticos para sua aprovação e realização.

No momento do convite para participação da pesquisa, o participante foi informado dos objetivos da mesma, de normas quanto ao sigilo das informações prestadas e divulgação dos dados (Resolução 196/96 do Conselho Nacional de Saúde). Após essas informações, foi solicitada a formalização do consentimento por meio do termo de consentimento livre e esclarecido.

\section{Procedimento de análise de dados}

Todos os itens respondidos no formulário de pesquisa pelas famílias foram submetidos ao software Statistical Package for the Social Sciences (SPSS) para Windows, com objetivo de proceder às análises preliminares. Neste artigo, por se tratar de delineamento descritivo, apenas utilizamos a frequência das respostas do questionário, com sua análise qualitativa.

\footnotetext{
A classificação baseada nas pesquisas das condições de vida (PCV) da Fundação Seade serviu de base para comparação e para a escolha das famílias.
} 


\section{Resultados}

\section{Identificação das famílias em fase de aquisição}

Das 50 famílias entrevistadas, $92 \%$ dos respondentes foram mulheres sozinhas, enquanto apenas $8 \%$ dos homens responderam sozinhos ao questionário. Nenhuma entrevista foi realizada com marido e mulher juntos. Por ser uma amostra de conveniência, tal distribuição dos entrevistados entre homens e mulheres justifica-se pela disponibilidade do integrante da família em responder à pesquisa no ato do convite. Não houve influência do pesquisador a fim de que um ou outro integrante da família respondesse.

Quanto ao tipo de moradia, das 50 famílias em fase de aquisição, 70\% moram em casa própria, 20\% moram em casa alugada e 10\% moram em casa cedida.

Quanto à religião das famílias entrevistadas, 56,3\% disseram adotar a religião católica, $35,4 \%$ adotam a religião evangélica, 2,1\% espírita kardecista, 2,1\% espírita umbanda e 2,1\% declararam-se sem religião.

Em Vitória, das 50 famílias em fase de aquisição entrevistadas, 82\% vivem na primeira união, $16 \%$ vivem na segunda união e $2 \%$ na terceira união. Nesta fase do ciclo vital da família, não foram encontrados viúvos, nem pais solteiros com filhos.

Quanto ao tipo de união, 66\% tiveram união no civil e no religioso, $18 \%$ apenas no civil e $16 \%$ disseram morar juntos sem formalização da união.

Em relação ao tempo de união, $56 \%$ dos casais estão juntos há menos de cinco anos, 22\% têm de 6 a 10 anos de união, 14\% têm de 11 a 15 anos, e $8 \%$ têm de 16 a 20 anos.

Quarenta por cento das famílias entrevistadas não têm filhos, enquanto $60 \%$ têm de 1 a 2 filhos. Nenhuma família tem mais de 2 filhos. Em relação a filhos de outras relações, $18 \%$ das famílias dizem que um dos cônjuges tem filhos de outra relação.

Quanto à escolaridade, 32\% dos homens e mulheres têm ensino superior completo, $28 \%$ e $22 \%$, respectivamente, de homens e mulheres são pósgraduados. $\mathrm{O}$ índice de não conclusão do ensino superior é maior para as mulheres $(26 \%)$ do que para os homens (12\%), ao contrário, embora em menores proporções, o percentil de mulheres (18\%) que concluíram o ensino médio é maior do que o dos homens (14\%). 
Quanto à profissão, respectivamente para homens e mulheres, temos que $8 \%$ e $10,5 \%$ são profissionais liberais, $36 \%$ e $26,3 \%$ são autônomos, e $56 \%$ e $63,2 \%$ são assalariados.

Das 50 famílias entrevistadas, apenas uma não quis relatar sua renda mensal. Dessa forma, temos que, das 49 famílias, 40,8\% têm renda entre 5 e 9 salários mínimos, $42,9 \%$ têm renda entre 10 e 20 salários mínimos e $16,3 \%$ têm renda variando de 21 a 30 salários. De modo que o maior mantenedor da renda familiar ainda é o homem. De acordo com os dados obtidos, $40 \%$ das famílias afirmaram que apenas o homem é responsável pela renda, 34\% relataram que a renda familiar é mantida pelo homem e complementada pela mulher, $8 \%$ disseram que a renda é mantida pela mulher e complementada pelo homem e $18 \%$ afirmaram que a renda é mantida por homem e mulher igualmente. Apenas $6,4 \%$ das famílias afirmaram que a renda familiar está comprometida por situação de desemprego, do homem.

Nas famílias entrevistadas, $70 \%$ das mulheres exercem função remunerada, sendo que, desse total, 65,8\% trabalham fora há mais de sete anos. Quanto à jornada de trabalho dessas mulheres, a maioria $(54,3 \%)$ trabalha de 5 a 8 horas, sendo que apenas $20 \%$ trabalham menos de quatro horas diárias. Quando questionadas por que trabalham, os maiores índices de respostas correspondem à realização pessoal $(37,1 \%)$, construir uma carreira $(31,4 \%)$ e por causa do dinheiro $(25,7 \%)$. Apenas $5,7 \%$ afirmaram trabalhar para ter uma ocupação. Das mulheres que não exercem função remunerada $(30 \%)$, os motivos se dão principalmente porque consideram prioridade a casa e os filhos $(33,3 \%)$ e atrapalharia os estudos $(33,3 \%)$.

\section{Sobre o relacionamento do casal em fase de aquisição}

No que diz respeito à interação do casal, $88 \%$ das famílias entrevistadas disseram que "a relação atual do casal é amorosa", 10\% afirmaram ser a relação amigável e apenas $2 \%$, desrespeitosa. Ainda, em $94 \%$ das famílias entrevistadas, há diálogo constante; em $4 \%$ das famílias, há diálogo difícil; e em $2 \%$, falta diálogo.

Quanto à vida sexual do casal, 70\% afirmaram que é muito boa; $22 \%$ optaram pela resposta razoável; $4 \%$ disseram estar abaixo das expectativas; e $4 \%$ dos entrevistados preferiram não responder a esse item. Nenhuma das famílias entrevistadas afirmou que não existe relacionamento sexual.

Perguntamos aos entrevistados qual seria o principal objetivo do 
casamento atualmente. Setenta por cento afirmaram a união do casal e formação da família; $22 \%$ afirmaram companheirismo e cuidado mútuo; e $8 \%$ disseram que o objetivo do casamento na atual fase em que vivem é enfrentar mudanças.

Sobre o lazer do casal das famílias em fase de aquisição, de acordo com os dados coletados, os casais priorizam o lazer conjunto com grande frequência e ainda se permitem programações em separado.

Grosso modo, os casais disseram não enfrentar dificuldades (42,9\%), mas os que a relataram, salientam dificuldades principalmente quanto à vida profissional $(26,5 \%)$ e dinheiro $(18,4 \%)$.

Quando perguntados sobre o que há de melhor na relação do casal, foram ressaltados, amor $(44,9 \%)$, companheirismo $(24,5 \%)$ e objetivos de vida em comum $(16,3 \%)$.

\section{Sobre a vida em familia}

Perguntadas $^{2}$ sobre as regras que são adotadas pelo casal em relação à educação dos filhos, 78,8\% das famílias com filhos responderam que as regras são discutidas e construídas pelo casal.

Como metas das famílias em fase de aquisição, em primeiro e segundo lugar, respectivamente, apareceram os itens, construir a família (58\%) e construir o patrimônio familiar (50\%).

Sobre o que há de melhor na família, as opções mais assinaladas foram carinho $(77,6 \%)$, respeito $(67,3 \%)$ e diálogo $(63,3 \%)$.

No momento das decisões importantes, $93,4 \%$ das famílias, de um total de 49 famílias que responderam a essa questão, afirmaram que homem e mulher decidem em conjunto.

Os valores destacados como importantes nas famílias vitorienses em fase de aquisição foram o amor entre o casal e os filhos (70\%), diálogo entre as pessoas da família (62\%) e preservação dos valores religiosos (48\%).

Se pudessem reclamar de alguma coisa em suas famílias, perguntamos de que o fariam. Os dois itens mais citados foram falta de tempo (54\%) e falta de dinheiro (18\%), sendo que nenhuma família reclamou de agressividade ou relacionamento ruim entre os membros, ainda, $36 \%$ do total de famílias respondentes disseram que não tinham do que reclamar.

\footnotetext{
Sessenta por cento do total das famílias responderam a esse item, visto ser essa a porcentagem das 50 famílias entrevistadas que têm filhos, uma vez que casal sem filhos também é considerado, por Cerveny e Berthoud (1997), como em fase de aquisição.
} 
Quanto aos rituais preservados pela família, os mais citados foram trocar presentes em datas comemorativas (78\%), lazer em comum (família nuclear) (64\%) e tomar junto as refeições (60\%).

Perguntadas sobre a programação de domingo, das 50 famílias entrevistadas, $42 \%$ dedicam-se ao lazer em comum, 36\% afirmaram que se reúnem em casa com parentes, e $20 \%$ ficam em casa em atividade comum.

No que diz respeito às atividades de lazer mais frequentemente realizadas pelas famílias, os entrevistados tinham uma lista com dez opções em que poderiam marcar até três alternativas. Dessa forma, as atividades mais destacadas foram assistir à tevê (74\%) em primeiro lugar; em segundo, visitar amigos e parentes (48\%); e, em terceiro, viajar (40\%). Nenhum dos entrevistados disse ir a teatro, museus ou exposições.

Sobre o momento em que pais e filhos se reúnem, observamos um maior encontro nos finais de semana e durante as refeições.

Das famílias entrevistadas, $70 \%$ disseram existir assuntos evitados nas conversas familiares. Em maior proporção, os assuntos evitados foram morte $(46 \%)$, separação $(26 \%)$ e violência $(20 \%)$.

Perguntamos às famílias quais acontecimentos foram marcantes e fizeram rever valores familiares. Os três itens mais citados foram, em ordem de relevância, nascimento de um membro, mudança de residência e morte.

As famílias foram questionadas quanto aos valores que são passados de uma geração a outra. Os mais assinalados foram a honestidade $(72 \%)$, a importância dos estudos (60\%), o cuidado com os mais velhos (32\%) e a "a família em primeiro lugar" (32\%). Os menos destacados foram preservação do patrimônio familiar (4\%), respeito à hierarquia (12\%) e virgindade antes do casamento (14\%).

Pedimos às famílias entrevistadas que escolhessem, de uma lista de 13, até três ditados populares que acreditavam serem verdadeiros para sua família. Dessa forma, os três mais citados foram "Cada um colhe o que planta" (58\%), "Quem casa, quer casa" (52\%) e "Deus dá o frio conforme o cobertor" (40\%).

Perguntadas sobre as dificuldades vividas pela família, dos 14 itens listados, os três mais citados foram preocupação com o futuro dos filhos (36\%), falta de tempo para o lazer (34\%), incerteza quanto à instabilidade financeira (32\%).

\section{Sobre os filhos pequenos}

Responderam a essa parte do formulário apenas os casais com filhos (30 famílias), e ainda desses, apenas 25 responderam aos itens do questionário, 
pois as famílias tiveram liberdade em escolher responder ou não às perguntas em qualquer momento da entrevista.

Dessa forma, a primeira pergunta dizia respeito à decisão de ter filhos. Das 25 famílias respondentes, em $72 \%$ dos entrevistados a decisão foi do casal.

Perguntadas sobre a chegada do primeiro filho, os respondentes, maioria mulheres, assinalaram que o primeiro filho alterou as tarefas, metas e funçôes da família, e também modificou temporariamente o relacionamento do casal. Foi salientado, ainda, que o filho melhorou o relacionamento do casal.

As famílias relataram que as atividades de lazer dos filhos são prioritariamente realizadas com a mãe, o pai e os amigos.

Dos cuidados rotineiros com o bebê, o pai e a mãe foram os que mais assumiram essas tarefas, seguidos pelos avós, em baixas proporções. Perguntados sobre quem assume a educação dos filhos, os mais destacados foram ambos os pais.

\section{Discussão e conclusões}

Identificação das famílias vitorienses de classe média em fase de aquisiçãa: a estrutura familiar

A maioria das famílias entrevistadas possui casa própria, apenas duas das famílias entrevistadas moram com outros parentes da família extensa (ex.: avós e tios), o que mostra uma tendência de afirmar a importância da família nuclear e o desejo de criar um modelo familiar próprio. Esta última característica é citada por Cerveny e Berthoud (1997) como típica à fase de aquisição, em que se marca o início e a singularidade de uma nova formação familiar.

A religião adotada pelas famílias foi predominantemente católica, característica tradicional, seguida da religião evangélica, o que está de acordo com o acentuado crescimento das religiōes chamadas evangélicas no Estado. As religiōes espíritas se mostraram como minoria nas famílias pesquisadas.

A maior parte das famílias é de primeira união, poucos cônjuges estão em segunda ou terceira união, e nenhuma família com pais solteiros foi encontrada, o que coloca o casamento como instituição forte. Gomes e Paiva (2003) e Féres-Carneiro (1998) salientam a importância do casamento como significação de vida e construção da identidade, frente a duas forças paradoxais que entremeiam as relaçóes do casal: a individualidade $\mathrm{X}$ a conjugalidade. Salientam, ainda, que muitas pesquisas têm mostrado o grande número de 
casamentos que vêm ocorrendo na sociedade atual a despeito da visão de alguns autores sobre a falência do casamento como união formalizada.

A maioria dos casais entrevistados (66\%) passou por ritual de casamento, civil e religioso, sendo pequeno o número de uniōes não formalizadas, Lopes, Menezes, Santos e Piccinini (2006) relatam que o ritual do casamento, em pesquisa realizada na Região Sul do Brasil, dá-se majoritariamente por opção dos próprios cônjuges e, em menor grau, por pressões sociais. Os autores ainda apontam, baseados em outros estudos:

Um ritual de casamento pode indicar a capacidade dos membros da família de fazer as mudanças necessárias de status e passar para estágios futuros do ciclo de vida familiar, em se tratando de famílias de classe média, em sociedades ocidentais. Além disso, a existência de um ritual simbolizando a escolha do(a) companheiro(a) pode fortalecer os laços emocionais do casal, o que confirma a literatura da área quanto à importância dos rituais familiares em geral (Lopes, Menezes, Santos \& Piccinini, 2006, p. 59-60).

$\mathrm{Na}$ maioria das famílias entrevistadas, homem e mulher têm ensino superior completo, com o número de pós-graduados ligeiramente aumentado para os homens. O homem também se mostrou como o maior responsável pelo sustento econômico, enquanto poucas mulheres se responsabilizam sozinhas pela renda da família. Em sua maioria, as mulheres completam a renda familiar. Diferente do observado por Cerveny e Berthoud (2002), em que as metas financeiras são atingidas a dois, a família de Vitória em fase de aquisição está atrelada ao modelo de provedor tradicional.

Nas profissões de homens e mulheres, prevaleceu o trabalho assalariado, sendo que a renda média das famílias esteve entre 5 e 30 salários mínimos. Das mulheres que não trabalham fora de casa, estar estudando (o que pode explicar a maior prevalência de mulheres com ensino superior incompleto) e dedicar-se exclusivamente a casa e aos filhos mostram-se os principais motivos. Observase uma tendência moderna nos casamentos atuais em que as mulheres ainda buscam complemento educacional e, em maior número, trabalham fora de casa em tempo integral, mas, apesar disso, aspectos tradicionais permanecem, por exemplo, o homem ser o principal responsável pelo sustento econômico da família.

\section{Dinâmica do casal em fase de aquisição}

O casal da família em fase de aquisição relata, de modo geral, constante diálogo e relação amorosa. Salientam que veem como objetivo do casamento, 
em maior grau, união do casal e formação da família e, em menor grau, companheirismo e cuidado mútuo. O primeiro, característica marcante da fase de aquisição, em que o jovem casal intenta construir seu modelo próprio de família, definindo papéis e funçôes de cada um dos cônjuges; o segundo se mostra como tendência atual, do casamento com caráter afetivo, em que os cônjuges se unem para viver melhor, com o intuito de um ser o cuidador do outro (Cerveny \& Berthoud, 1997; Perlin \& Diniz, 2005).

Os entrevistados ainda apontaram o sexo como muito bom, o que não está de acordo com a literatura. Jablonski (2003) afirma que o sexo foi algo mal avaliado entre casais. Papalia e Olds (2000) destacam que, muitas vezes, dizer que o sexo vai bem mascara o que realmente acontece, pois, em muitas pesquisas, os casais salientam o sexo como muito bom, com vergonha de falar das frustrações do casal. O que observamos, em nossa pesquisa, foi o maior relato das mulheres de relacionamento sexual ótimo, enquanto os homens destacaram mais as opções "razoável" e "abaixo das expectativas". No entanto, como o número de homens respondentes foi reduzido, não podemos dizer, de modo mais exato, se essa relação se confirma.

Os casais em fase de aquisição priorizam atividades de lazer juntos, o que, segundo Féres-Carneiro (1998), é uma característica mais valorizada em cônjuges de primeira união, pois casais que já vêm de outras uniōes priorizam programas em separado com amigos ou individualmente.

Grosso modo, os casais não relataram enfrentar dificuldades. Entre os que enfatizaram estarem passando por problemas, as principais dificuldades dizem respeito à vida profissional e ao dinheiro, o que está de acordo com a pesquisa realizada por Cerveny e Berthoud (1997) no Estado de São Paulo, em que uma das metas das famílias é buscar estabilidade financeira.

\section{Dinâmica familiar}

Dos casais com filhos (60\%), a maioria destacou, no que diz respeito às regras adotadas sobre educação, que são construídas e discutidas pelo casal. Concordando com Cerveny e Berthoud (1997, p. 191) que, tratando da mesma questão, afirmam, com o mesmo índice de respostas em sua pesquisa, "As famílias em fase de aquisição tentam uma inovação na forma de educar seus filhos, de certa forma rejeitando os modelos das famílias de origem", criando seu próprio estilo.

A fase de aquisição é "[...] permeada pelo processo de construção" 
(Cerveny \& Berthoud, 1997 , p. 50), em que a família se preocupa em construir, por exemplo, as carreiras profissionais, o patrimônio familiar, a independência das suas famílias de origem e os papéis assumidos por cada um na relação conjugal. Corroborando com esse dado teórico, as metas principais destacadas nas famílias de Vitória em fase de aquisição foram construir a família e construir o patrimônio familiar, o que ainda é confirmado quando salientam, como um dos principais objetivos do casamento, a união do casal e a formação da família.

Destacados como o que há de melhor na família, os dados indicam: carinho, respeito e diálogo. Como salienta Cerveny e Berthoud (1997), os chamados "ideais românticos", característicos da Modernidade, fazemse presentes nos jovens casais, o que não se mostrou diferente em nossa pesquisa.

\section{Dinâmica das familias com filhos pequenos}

Aos casais com filhos perguntamos sobre suas relações, tarefas e papéis. Os dados indicam que a decisão de ter filhos foi, de modo geral, de ambos, homem e mulher. A decisão de ter filhos, marcada como algo escolhido pelo casal, reforça a tese de que os métodos anticoncepcionais estão bastante acessíveis para essa classe econômica, assim como informações sobre o planejamento familiar.

A maior parte dos entrevistados avalia como positiva a chegada do primeiro filho, salientando as mudanças que provoca, trazendo necessidade do rearranjo de funçóes e papéis desempenhados não só pelo casal, que se tornam mãe e pai, mas pelos outros membros da família extensa que, além de sogro e sogra, agora também serão avós (Cerveny \& Berthoud, 1997).

Os cuidados com o bebê foram majoritariamente desempenhados por mãe e pai juntos. Isso acentua uma mudança nos papéis e funções da família moderna, em que as tarefas de cuidado do lar e dos filhos estão mais igualitariamente distribuídas, reflexo da maior atuação das mulheres no mercado de trabalho, embora ainda se observe representações de papéis ligadas às questões de gênero, com o predomínio da mulher em atividades domésticas e o marido como resolutor de problemas extralar (Perlin \& Diniz, 2005; Cerveny \& Berthoud, 1997).

\section{Valores familiares}

Entre os valores mais destacados estão amor entre o casal e os filhos, diálogo entre as pessoas da família e preservação dos valores religiosos. Os 
dois primeiros salientam-se como base de um relacionamento adequado e estão de acordo com o ideal de família feliz naturalizado ao longo do tempo. A preservação dos valores religiosos acentua um caráter conservador nas famílias de Vitória em fase de aquisição.

As maiores preocupações das famílias estiveram ligadas à falta de tempo e incerteza quanto à estabilidade financeira, aliadas às mudanças vividas pela família, que acontecem muitas vezes quando se está constituindo um modelo familiar próprio (Cerveny \& Berthoud, 1997; Cerveny \& Berthoud, 2002).

Como principal programação de domingo, destacou-se o lazer em comum, prioritariamente em casa, com parentes e amigos. Isso mostra hábitos mais corriqueiros com a valorização de atividades comuns. O grande destaque do lazer ficou para a televisão, um fato interessante nas famílias em fase de aquisição da cidade, uma vez que, no formulário de pesquisa, a opção ir a museu, teatros e exposiçóes não foi citada por nenhuma família participante.

Como fatos que fizeram as famílias reverem valores e precisarem remanejar a dinâmica familiar, os dados indicaram nascimento, mudança de residência e morte, aspectos que podem alterar papéis e funções desempenhados pelos membros da família.

Os valores que as famílias consideram passados de uma geração a outra são honestidade, importância dos estudos, cuidado com os mais velhos e "a família em primeiro lugar”. Os menos destacados foram preservação do patrimônio familiar, respeito à hierarquia e virgindade antes do casamento. Observamos o rompimento com antigas tradiçôes, como virgindade antes do casamento e a manutenção de padrões como a "família em primeiro lugar" e o cuidado com os mais velhos. Dessa forma, acentua-se a tradição convivendo com características da Modernidade nas famílias atuais.

Pedimos às famílias que escolhessem de uma lista os ditados que mais definiriam sua família. Dessa forma, os mais assinalados foram "Cada um colhe o que planta", que, de acordo com Cerveny e Berthoud (1997, p. 193), "[...] demonstra o caráter empreendedor necessário ao alcance das metas planejadas nessa fase"; "Quem casa quer casa", e "Deus dá o frio conforme o cobertor", em que se pode salientar, como também indicam Cerveny e Berthoud (Ibidem), a busca por estabilidade e segurança. Podese destacar também a relação entre o ditado "Quem casa quer casa" com o alto índice de casais em fase de aquisição (70\%) que têm casa própria e moram apenas o casal com seus filhos. 


\section{Considerações finais}

As famílias pesquisadas, de modo geral, de acordo com o exposto na literatura, apresentam o objetivo de construir seu modelo próprio de ser família, considerando os aspectos positivos do casamento, priorizando atividades em comum e o bom convívio dos cônjuges. Como dinâmica das famílias vitorienses em fase de aquisição, pode-se destacar o objetivo de construir a família e seu patrimônio, em que os filhos e a estabilidade financeira mobilizam e preocupam a família, ao mesmo tempo em que instigam a lutar para atender aos filhos e buscar maior satisfação no âmbito econômico. Os dados ainda indicam valorização acentuada dos aspectos positivos nas relações familiares e o predomínio da divisão de funções de acordo com o gênero, embora possam se observar tímidos movimentos de modernização, por exemplo, quanto às decisões tomadas pela família que, em maior grau, são feitas por homem e mulher em conjunto.

Quanto à dinâmica das famílias com filhos, tem-se um maior envolvimento dos pais em atividades antes prioritariamente desempenhadas pelas mães. Assim observamos uma mudança mais acentuada no arranjo familiar para a chegada do primeiro filho, em que ambos os cônjuges já tomam decisões em conjunto desde antes da concepção do filho.

Os valores familiares demonstram que a ideologia familiar gira em torno do amor, diálogo e valores religiosos, em que se destacam atividades tradicionais, como fazer em família as refeições, e usuais, assistir à tevê como principal forma de lazer, como preservadas pelas famílias. Morte, separação e violência aparecem como tabus para as famílias, caracterizadas pelos ditos populares, com um modo empreendedor de buscar autonomia, segurança e estabilidade frente aos desafios do conjugalidade moderna.

A família de Vitória em fase de aquisição, de acordo com os dados levantados, mostrou-se mais tradicional, com conflitos relacionados a assuntos extradinâmica familiar, como dinheiro e satisfação profissional. Destacam-se os aspectos como amor, diálogo e respeito, ideais românticos, perpassando as relações familiares das famílias em fase de aquisição, o que indica adequação nos relacionamentos entre os membros da família.

Ao apresentarmos elementos sobre a dinâmica, estrutura e funcionamento da família dos extratos médios da população de Vitória que se encontram na fase de aquisição, intentamos fornecer material de estudo para pesquisadores, como salientam Cerveny e Berthoud (2002, p. 14), importante para a "construção de uma Psicologia da família brasileira, preenchendo a lacuna hoje existente nessa área do conhecimento em nosso país”. 


\section{Referências}

Carter, B. \& McGoldrick, M. (1995). As mudanças no ciclo de vida familiar: uma estrutura para a terapia familiar. (Maria Adriana Veríssimo Veronese, trad.). Porto Alegre: Artes Médicas.

Cerveny, C. M. O., Berthoud, C. M. E. \& col. (1997). Família e ciclo vital: nossa realidade em pesquisa. São Paulo: Casa do Psicólogo.

Cerveny, C. M. O. \& Berthoud, C. M. E. (2002). Visitando a família ao longo do ciclo vital. São Paulo: Casa do Psicólogo.

Conselho Nacional de Saúde (Brasil). Resolução no 196 de 10 de outubro de 1996. Diretrizes e normas regulamentadoras de pesquisas envolvendo seres humanos. Diário Oficial da República Federativa do Brasil, Brasília, 16 out. 1996. Recuperado em 1 de julho de 2009, de <http://conselho.saude.gov.br/ docs/Resolucoes/Reso196.doc>.

Féres-Carneiro, T. (1998). Casamento contemporâneo: o difícil convívio da individualidade com a conjugalidade. Psicologia: reflexão e crítica, 11 (2), 379-394.

Gomes, I. C. \& Paiva, M. L. S. C. (2003). Casamento e família no século XXI: possibilidade de holding? Psicologia em Estudo, 8 (número especial), 3-9.

Jablonski, B. (2003). Afinal, o que quer um casal? Algumas considerações sobre o casamento e a separação na classe média carioca. In: Féres-Carneiro, T. (org.). Familia e casal: arranjos e demandas contemporâneas. (pp. 141-168). Rio de Janeiro: EDPUC/Loyola.

Lopes, R. C. S., Menezes, C., Santos, G. P. \& Piccinini, C. A. (2006). Ritual de casamento e planejamento do primeiro filho. Psicologia em Estudo, 11 (1), $55-61$.

Narvaz, M., Koller, S. H. (2006). A invenção da família. Revista Pensando Familias, 7 (9), 121-134.

Papalia, D. E. \& Olds, S. W. (2000). Desenvolvimento humano. (Daniel Bueno, trad.). Porto Alegre: Artes Médicas Sul.

Perlin, G. \& Diniz, G. (2005). Casais que trabalham e são felizes: mito ou realidade? Psicologia Clínica, 17 (2), 15-29.

Prado, D. (1981). O que é família? São Paulo: Brasiliense. 